
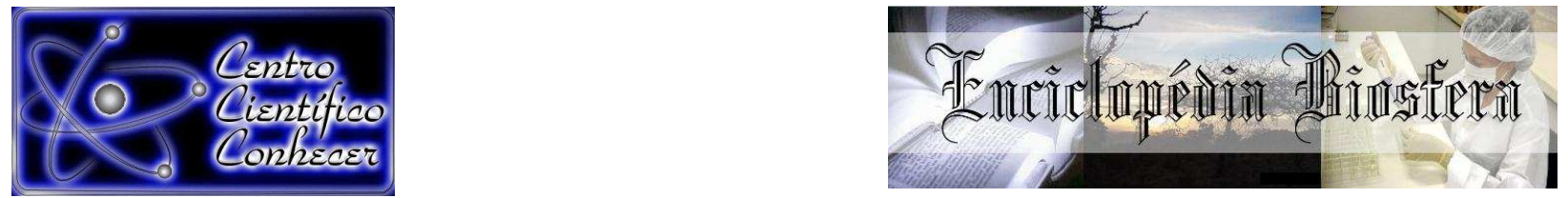

\title{
IDENTIFICAÇÃO DE PONTOS DE CONTAMINAÇÃO POR Clostridium estertheticum EM AMBIENTES MATADOUROS FRIGORÍFICOS ${ }^{6}$
}

\author{
Luciano Pereira Paes ${ }^{1}$ Wesdras Martins dos Santos ${ }^{2}$, Renan de Souza Soares ${ }^{3}$, \\ Marcus Vinícius Forzani Araújo ${ }^{4}$, Aysha Jussara Ivonilde Carrim ${ }^{5}$
}

1, 2 Graduado em Biologia, Universidade Estadual de Goiás, Anápolis. Especialista em Microbiologia aplicada: indústria e meio ambiente, UniEvangélica Centro Universitário, Anápolis/Goiás

3, 4 Mestre do Programa de Pós-Graduação em Ciências Ambientais,Pró-reitora de Pesquisa, Universidade Federal de Goiás

5 Doutoranda do Programa de Pós-Graduação em Ciências Ambientais,Pró-reitora de Pesquisa, Universidade Federal de Goiás (acarrim@gmail.com). Goiânia, Brasil

6 este trabalho é resultado do trabalho de conclusão de curso realizado na UniEvangélica.

\section{Recebido em: 08/04/2016 - Aprovado em: 30/05/2016 - Publicado em: 20/06/2016} DOI: 10.18677/Enciclopedia_Biosfera_2016_132

\begin{abstract}
RESUMO
Considerando a expressiva ocorrência do problema de deterioração que prejudica a exportação brasileira de carne bovina "in natura", aliado ao enorme prejuízo econômico e dificuldade de cultivo e isolamento do agente causal, fez-se necessário a utilização da técnica de Reação em Cadeia da Polimerase (PCR) para a detecção em tempo hábil do Clostridium estertheticum. Foram analisadas 3.938 amostras provenientes de matadouros-frigoríficos, em sete prováveis focos de contaminação. A extração do DNA foi realizada com o Kit comercial (Roche Applied Science®). Os "primers" utilizados: "Forward e Reverse", que amplificam um fragmento gênico de 641 pares de base. Os resultados indicaram uma positividade de 3,12\%, que apesar de baixa, confirma que o $C$. estertheticum encontra-se disseminado no ambiente dos matadouros-frigoríficos destacando que a sua presença relativamente maior nos pontos: câmaras frigoríficas, superfície de corte cárneo e sala de matança, que estão relacionados ao gênero o qual o $C$. estertheticum pertence e seu modo de sobrevivência. Os pontos de coleta foram significativos que de acordo com os resultados obtidos levam a uma necessidade de revisão dos procedimentos operacionais padrões relacionados principalmente com as etapas de esfola, desossa, embalagem e estocagem dos cortes cárneos.
\end{abstract}

PALAVRAS-CHAVE: carne embalada a vácuo, contaminante, PCR.

\section{IDENTIFICATION OF CONTAMINATION SPOTS BY Clostridium estertheticum IN SLAUGHTERHOUSES REFRIGERATED ENVIRONMENTS}

\footnotetext{
ABSTRACT

Considering the significant incidence of the problem of deterioration that affects Brazilian beef"in natura" exportation, allied with the huge economic loss and the difficulty in culturing and isolation of the causative agent, it was necessary to use the ENCICLOPÉDIA BIOSFERA, Centro Científico Conhecer - Goiânia, v.13 n.23; p.1742 2016
} 
technique of Polymerase Chain Reaction (PCR) for nimble detection of Clostridium estertheticum. It was analyzed 3938 samples from slaughterhouses refrigerated, collected in seven probable sources of contamination. DNA extraction was performed using the commercial kit (Roche Applied Science ${ }^{\circledR}$ ). The "primer" uses "Forward and Reverse," which amplify a gene fragment of 641 base pairs. The results showed a positivity of $3.12 \%$, although low, it confirms that $C$. estertheticumis widespread in the refrigerated environment of slaughterhouses highlighting their presence in the relatively larger point: cold rooms, meaty cut surface and room killing, which are related to the genus to which $C$. estertheticum belongs and their way of survival. The sampling sites were significant according to the results, suggesting the needed to revise the standard operating procedures relating mainly to the stages of skinning, boning, packaging and storage of meat cuts.

KEYWORDS: contaminant, PCR, vacuum-packaged meat.

\section{INTRODUÇÃO}

A produção de carne bovina é uma importante área econômica geradora de renda no Brasil. O setor atingiu um aumento de $417 \%$ no volume de exportações de 1995 a 2015, com isso possui significante peso no PIB nacional e consolidou o Brasil como um dos maiores exportadores de carne bovina do mundo, consequência de investimentos em pesquisas na área de produção e preservação de alimentos (MACHADO et al. 2015). Dentre o desenvolvimento de técnicas de conservação, uma das mais modernas e eficientes tecnologias de conservação e comercialização da carne é o uso de embalagens a vácuo, que permite uma vida de prateleira de até 45 dias, sendo então um dos tipos mais utilizados para exportação. Entretanto, contaminações nesse tipo de acondicionamento por micro-organismos psicrotolerantes estão relacionadas à deterioração da carne e consequente perda econômica, avaria promovida principalmente por bactérias do tipo psicrofílicas pertencentes ao gênero Clostridium, normalmente Clostridium estertheticum (ADAM et al., 2013; MILLS et al., 2014, YANG et al., 2014).

As vias de acesso de espécies de Clostridium ao ambiente de matadouro é, principalmente, o contato com solo, fezes e couro contaminados (BOLTON et al., 2015). Normalmente, grande parte destes problemas está relacionada aos ambientes voltados ao processamento da carne, (equipamentos e manipuladores) além de itens como a água, transporte inadequado aliado a condições precárias de refrigeração, seccionamento, descongelamento e outras condições técnicas e higiênicas que, quando inadequadamente limpos ou manipulados, favorecem a colonização por micro-organismos deteriorantes, podendo inclusive favorecer a uma contaminação cruzada (HERNÁNDEZ- MACEDO et al., 2011; SILVA et al., 2012). Durante a deterioração ocorre a distensão da embalagem a vácuo (Figura 1) por conta dos compostos liberados pela carne, em especial gás hidrogênio e gás carbônico (MOSCHONAS et al., 2011) 


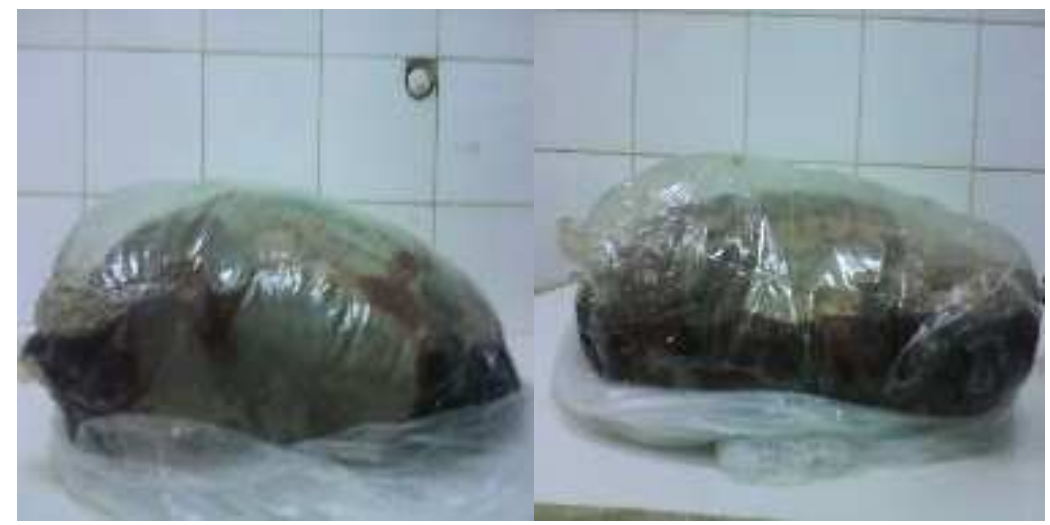

FIGURA 1 - Embalagens a vácuo tufadas envolvendo cortes cárneos.

Fonte: Elaborada pelos autores

O micro-organismo C. estertheticum classificado por Collins no ano de 1992, consiste em bactérias na forma de bastonetes gram-positivas, móveis, ocorrem isoladamente ou em pares, formam endósporos ovais, subterminais, terminais ou centrais, crescem a uma temperatura entre 1 a $15^{\circ} \mathrm{C}$, com nenhum crescimento em $22^{\circ} \mathrm{C}$, é estritamente anaeróbico e beta-hemolítico, com a capacidade de sobreviver a uma temperatura de $80^{\circ} \mathrm{C}$ durante 10 minutos devido à sua forma esporulada. $\mathrm{O} C$. estertheticum ao contrário de outras bactérias do mesmo gênero, não produz toxinas sendo, porém, seus esporos encontrados em embalagens a vácuo resistindo ao $\mathrm{pH}$ normal da carne durante quatro semanas (COLLINS et al. 1992, HELPS et al. 1999, BRODA et al. 2002, ADAM et al., 2013). Devido a dificuldades de isolamento e cultivo de $C$. estertheticum em meio de cultura, a forma mais segura de detecção do agente caracteriza-se pela extração do DNA seguido pelo uso de técnicas moleculares (BONKE et al., 2016).

Detectar a bactéria $C$. estertheticum torna-se de fundamental importância, uma vez que o prejuízo financeiro ocasionado por sua ação é bem significativo. Diante desta importante realidade para a economia brasileira o presente trabalho possui o objetivo de detectar $C$. estertheticum, por meio da Reação em Cadeia da Polimerase (PCR), a fim de identificar diferentes pontos de contaminação em ambientes de matadouros frigoríficos.

\section{MATERIAL E MÉTODOS}

\section{Coleta e Condicionamento das Amostras}

Para a elaboração de um levantamento dos principais pontos de contaminação por Clostridium estertheticum foram coletadas de forma randômica 3.938 amostras oriundas de sete prováveis pontos de contaminação pelo referido agente em ambientes de matadouros frigoríficos no período de outubro de 2009 a outubro de 2010. As amostragens dos pontos de coleta advieram de 32 unidades matadouros-frigoríficos pertencentes a cinco grupos industriais habilitados a realizar comércio internacional de carnes e derivados, localizados em nove estados brasileiros. A distribuição das unidades frigoríficas e porcentagem total das amostras 
analisadas por estado, bem como a classificação e quantidade dos pontos coletados estão representados na Tabela 1 e na Figura 2, respectivamente.

TABELA 1 - Distribuição das unidades frigoríficas e porcentagem do total das amostras por estado.

\begin{tabular}{lllllllllll} 
Estados & GO & MT & MS & PA & RO & SP & MG & BA & TO & Total \\
Unidades frigoríficas & 5 & 6 & 4 & 2 & 1 & 9 & 2 & 1 & 2 & 32 \\
$(\%)$ & 16 & 19 & 13 & 6 & 3 & 28 & 6 & 3 & 6 & 100 \\
\hline
\end{tabular}

Estas amostras foram coletadas por funcionários dos próprios frigoríficos e encaminhadas ao Laboratório de Biologia Molecular do Centro de Pesquisas em Alimentos da Escola de Veterinária da Universidade Federal de Goiás. (CPA/EV/UFG). Visando caracterizar as empresas, sem identificá-las, foram adotadas letras e números representando cada Grupo e Unidade frigorífica respectivamente. Cada grupo frigorífico foi composto por unidades e em cada unidade o número de amostras analisadas.

1

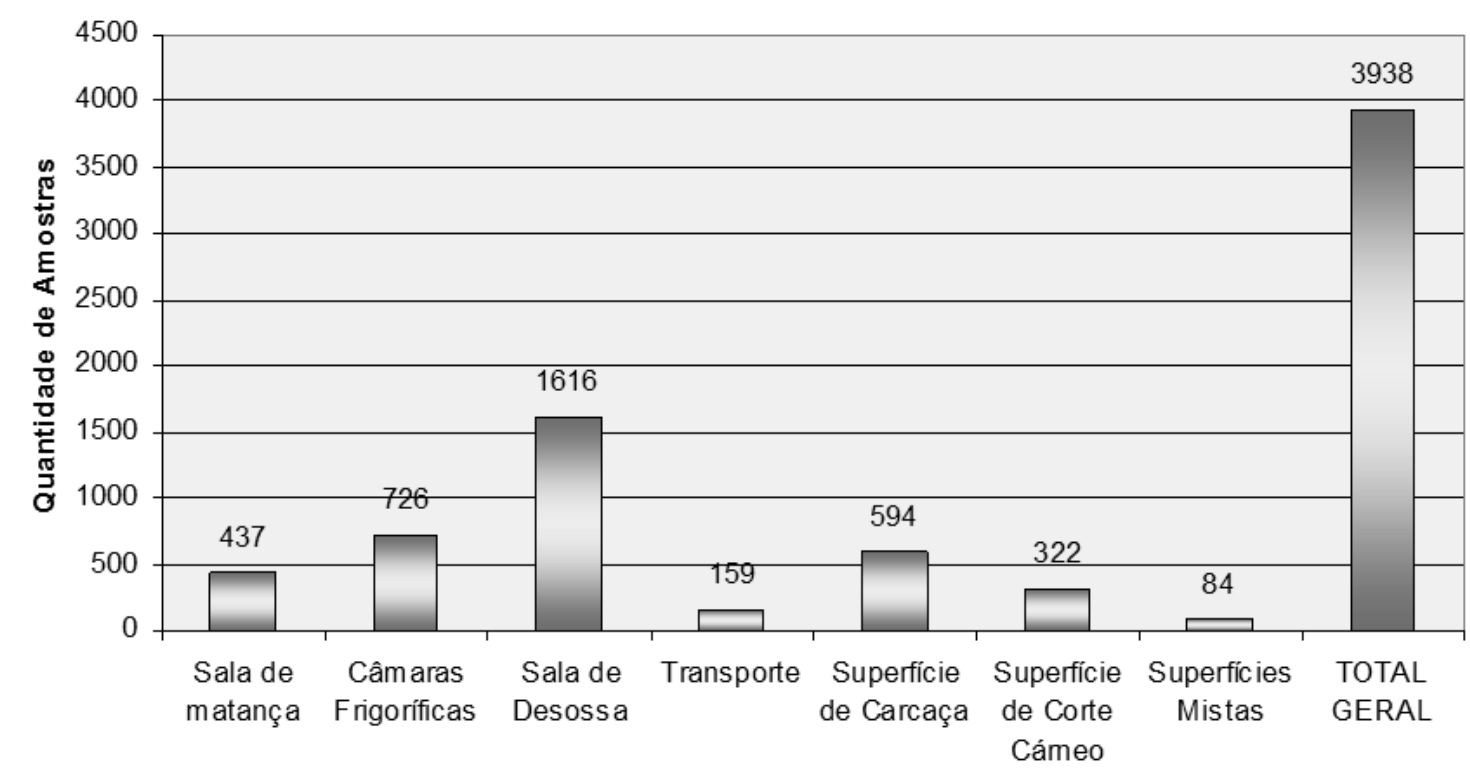

FIGURA 2 - Locais e quantidade de amostras de ambientes de processamentos de produtos cárneos de acordo com os pontos de coleta oriundos de diversas unidade frigoríficas dos Estados brasileiros. Goiânia (GO) 2010

A coleta foi procedida com a utilização de swabs ou esponjas umedecidas em solução conservadora esterilizada (solução salina a $0,85 \%$ e pH 7,0), realizando-se esfregaços em áreas correspondentes a $100 \mathrm{~cm}^{2}$ ou $10 \mathrm{~cm}^{2}$, e acondicionada em tubos ou sacos plásticos próprios esterilizados. No laboratório, as amostras foram homogeneizadas dentro da câmara de fluxo laminar utilizando vórtex, retirando-se, em seguida, $1,5 \mathrm{~mL}$ da amostra que foram acondicionadas em tubos previamente esterilizados e identificados.

\section{Identificação Molecular}

Após a sedimentação da amostra por centrifugação a 10.000 rpm/15min em tubos eppendorf, o sobrenadante foi descartado e o sedimento ressuspendido em 
450 $\mu \mathrm{L}$ de tampão Tris-EDTA (TE, $10 \mathrm{mM}$ Tris, $1 \mathrm{mM}$ EDTA, PH 8,0). Para a lise da parede celular foram adicionados $50 \mu \mathrm{L}$ de solução de lisozima com a seguida homogeneização das amostras em vórtex e deposição dos tubos em banho-maria a $37^{\circ} \mathrm{C}$, por 12 horas.

A extração de ácidos nucléicos foi realizada por meio da utilização do High Pure PCR Template Preparation Kit $\left(\right.$ Roche $\left.^{\odot}\right)$. Para avaliar a qualidade do DNA extraído foi realizada observação em gel de eletroforese (agarose a 0,8\%), amostras com concentração superior a $100 \mathrm{ng} / \mu \mathrm{L}$ de DNA foram diluídas com tampão TE (TrisEDTA) até a obtenção da concentração ideal. A estimativa de concentração das amostras foi obtida tendo como referência o marcador de massa molecular High DNA Mass Ladder (Invitrogen ${ }^{\mathrm{TM}}$ ), que forma bandas contendo: 400ng, 240ng, 160ng, 120ng, 80ng e 40ng de DNA.

Como controles positivos das reações de PCR foram utilizadas amostras de DNA genômico extraído a partir de cepas de referências adquiridas junto a DSMZ (Coleção Alemã de Micro-organismos e Culturas Celulares, Braunschweig, Alemanha). Para C. estertheticum utilizou-se a cepa de referência DSM 8809 e como controle negativo da reação foi utilizada água Mili-Q esterilizada. O processo de amplificação foi realizado em termociclador Programmable Thermal Controller (MJ Research Inc®), seguindo o programa referente ao protocolo sugerido por HELPS et al. (1999) com a utilização do "Revised forward (RFP) e Revised reverse primer (RRP)" desenvolvidos por Helps (1999), que anelam as posições 173-197 e 813-792, respectivamente, da subunidade 16S rDNA de $C$. estertheticum, no de acesso no GenBank S46734, fornecendo um produto de 641 pares de base (pb).

Para leitura dos resultados as amostras testadas, assim como, o controle positivo da reação, foram comparadas visualmente a um padrão de peso molecular que contém bandas de 100 em 100 pares de base (100bp DNA Ladder Invitrogen $\AA$ ). As amostras foram consideradas como positivas quando a banda amplificada correspondia à $641 \mathrm{pb}$, como o demonstrado na Figura 3.

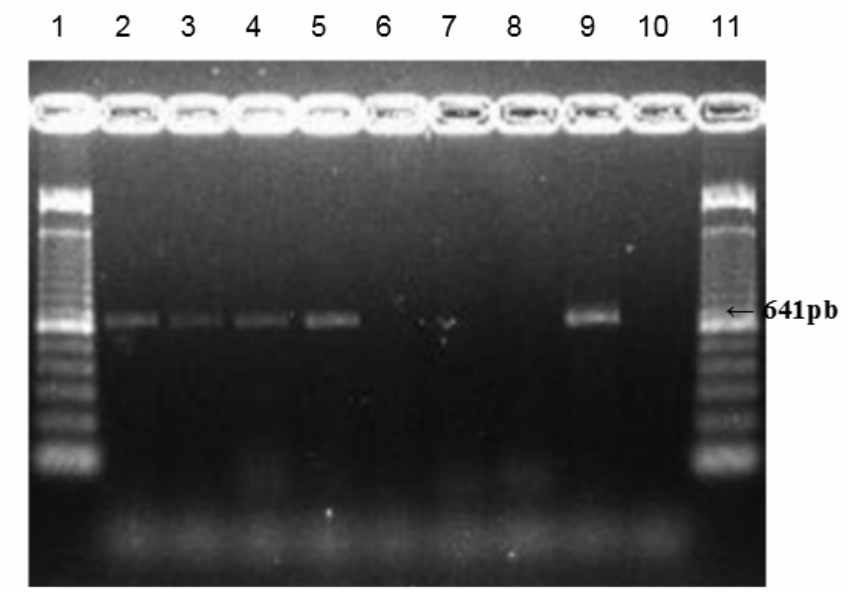

FIGURA 3- Gel de eletroforese de produtos de PCR de 641 pb do $16 \mathrm{~S}$ rDNA de Clostridium estertheticum. Canaletas 1 e 11: marcador molecular 100pb. Canaletas 2, 3, 4 e 5: amostras positivas; Canaletas 6, 7 e 8: amostras negativas; Canaleta 9: controle positivo da reação e Canaleta 10: controle negativo da reação.

Fonte: Elaborada pelos autores 


\section{RESULTADOS E DISCUSSÃO}

Observando os dados contidos na Tabela 2 verifica-se uma baixa positividade geral $(3,12 \%)$ com alta negatividade $(96,88 \%)$ para a presença do DNA de Clostridium estertheticum nos diferentes pontos de coleta analisados. Entretanto, observa-se, que a positividade dos resultados foi relativa e subsequentemente maior nos pontos de coleta: câmaras frigoríficas, superfícies de cortes cárneos e sala de matança, seguidos em menor proporção por superfícies mistas, superfícies de carcaças e sala de desossa. Estes resultados confirmam a hipótese da ocorrência de contaminação cruzada dentro da indústria frigorífica como relatado por MOURA et al. (2015) e BOLTON et al. (2015). De acordo com os autores, os microorganismos presentes na pele do animal e nos equipamentos utilizados na sala de matança, são disseminados para os diversos setores da indústria frigorífica devido às falhas operacionais, além da possibilidade de propagação por meio de contaminação ambiental no fluxograma de produção. O procedimento de retirada do couro, através da utilização do rolete, é considerado por BRODA et al. (2002) como a principal fonte de contaminação da carcaça.

TABELA 2. Distribuição dos resultados de Reação em Cadeia da Polimerase para detecção do DNA de Clostridium estertheticum de acordo com os pontos de coleta de amostras.

\begin{tabular}{lcccccc}
\hline \multirow{2}{*}{ Pontos de Coleta } & \multicolumn{6}{c}{ Resultados da PCR } \\
\cline { 2 - 7 } & \multicolumn{5}{c}{ Valores Absolutos } & \multicolumn{3}{c}{ Valores Relativos (\%) } \\
\cline { 2 - 7 } & Positivos & Negativos & Total & $\begin{array}{c}\text { Positivos } \\
(\%)\end{array}$ & $\begin{array}{c}\text { Negativos } \\
(\%)\end{array}$ & $\begin{array}{c}\text { Total } \\
(\%)\end{array}$ \\
\hline $\begin{array}{l}\text { Sala de matança } \\
\text { Câmaras }\end{array}$ & 12 & 425 & 437 & 2,75 & 97,25 & 100 \\
Frigoríficas & 67 & 660 & 726 & 9,23 & 90,77 & 100 \\
Sala de Desossa & 21 & 1595 & 1616 & 1,30 & 98,70 & 100 \\
Transporte & 0 & 159 & 159 & 0,00 & 100,00 & 100 \\
$\begin{array}{l}\text { Superfície de } \\
\text { Carcaça }\end{array}$ & 9 & 585 & 594 & 1,52 & 98,48 & 100 \\
$\begin{array}{l}\text { Superfície de } \\
\text { Corte Cárneo }\end{array}$ & 12 & 310 & 322 & 3,73 & 96,27 & 100 \\
$\begin{array}{l}\text { Superfícies } \\
\text { Mistas }\end{array}$ & 2 & 82 & 84 & 2,38 & 97,62 & 100 \\
TOTAL & 123 & 3816 & 3938 & 3,12 & 96,88 & 100 \\
\hline
\end{tabular}

Os resultados de maior positividade obtidos neste estudo para os pontos de coleta classificados como "Câmaras Frigoríficas" e "Sala de Desossa", estão de acordo com os resultados obtidos por BRODA et al. (2002) e podem ser relacionados ao fato do $C$. estertheticum ser um micro-organismo telúrico e, ao mesmo tempo psicrofílico, estando, portanto, vinculado ao meio onde é naturalmente encontrado, evidenciando sua presença em superfícies com maior possibilidade de contaminação pelo solo e fezes e que apresentam maior grau de dificuldade para a ENCICLOPÉDIA BIOSFERA, Centro Científico Conhecer - Goiânia, v.13 n.23; p.1747 2016 
realização das operações de limpeza e sanitização. Ressalta-se, entretanto, que a falta de controle da temperatura ideal nas salas de desossa $\left(<15^{\circ} \mathrm{C}\right)$ e câmaras frigoríficas $\left(<5^{\circ} \mathrm{C}\right)$ como verificado por ADAM et al. (2013), associadas à condição de anaerobiose dos cortes cárneos embalados a vácuo, propiciam condições ideais para que o micro-organismo assuma a forma vegetativa e se multiplique (ADAM et al., 2011).

A presença do DNA do C. estertheticum obtida para amostras coletadas nos pontos como superfície de carcaça, superfície de corte cárneo e em outros pontos de coleta permeáveis ao oxigênio, tais como superfícies mistas, deve-se à capacidade do $C$. estertheticum esporular, o que the permite sobreviver em condições de aerobiose e anaerobiose facultativa em temperaturas baixas, conforme descrito por MILLS et al. (2014). Além disso, conforme relata BOLTON e colaboradores (2015), a esterilização dos maquinários e instalações frigoríficos é feita geralmente apenas com ácido peracético. Desta forma, a não implementação de novos procedimentos alternativos que combinem outras estratégias de inativação de esporos de micro-organismos pode contribuir para uma disseminação do $C$. estertheticum por contaminação cruzada nas indústrias frigoríficas, como ressaltado por HEYNDRICKX (2011). Verifica-se, em relação ao grupo de amostras denominado "Transporte" que o DNA do $C$. estertheticum não foi detectado, demonstrando que a higienização dos veículos é realizada de forma satisfatória.

Os resultados obtidos no presente estudo, em relação aos focos de contaminação: sala de matança, sala de desossa, superfície de carcaça e superfície de corte cárneo revelaram em sua totalidade um grau de positividade média $(2,26 \%)$ é equivalente aos resultados encontrados por BOLTON et al. (2015), cuja positividade foi de $1,77 \%$. Entretanto, difere bastante com o resultado encontrado por BONKE et al. (2016), 34,4\%. A diferença na positividade entre os resultados comparados é devida, provavelmente, à melhoria dos procedimentos no processo de higienização, os chamados sistemas de: "Boas Práticas de Fabricação" (BPF) e "Análise de Perigos e Pontos Críticos de Controle" (APPCC) que foram incorporados à rotina de limpeza e sanitização após a obtenção dos primeiros resultados.

Apesar de 0 C. estertheticum ser considerado como o principal agente deteriorante de carnes bovinas, faz-se necessário um estudo mais detalhado para outros agentes relacionados, como por exemplo, as espécies Carnobacterium, Lactobacillus, Leuconostoc, como também gêneros da família Enterobacteriaceae, que estão relacionados ao tufamento de embalagem a vácuo (PATHAKOS et al., 2015).

Apesar da frequência de positividade relativamente baixa em relação a alguns estudos, os resultados obtidos demonstram a necessidade de melhorias nos procedimentos de higienização para impedir a contaminação cruzada, conforme discorre HEYNDRICKX (2011). Esta forma de resistir às condições adversas do meio permite ao agente permanecer nos setores industriais, mesmo que em baixos percentuais, tornando ativos os focos de contaminação e mantendo a possibilidade de deterioração dos produtos cárneos (YANG et al., 2014).

\section{CONCLUSÕES}

Com base nos dados obtidos foi possível concluir que apesar de todas as medidas adotadas pelos programas rotineiros de limpeza e sanitização, a positividade apresentada indica a disseminação do Clostridium estertheticum no ambiente dos matadouros-frigoríficos, considerando que os pontos de controle 
analisados foram efetivos para o monitoramento, haja vista que os resultados justificam a revisão dos procedimentos operacionais padrão, relacionado principalmente com as operações de esfola, desossa, embalagem e estocagem dos cortes cárneos.

Outro ponto a ser observado é em relação à correta manipulação, higienização e manutenção dos equipamentos por parte dos manipuladores, que vão desde o uso com vestimentas adequadas à limpeza e armazenamento de utensílios portáteis como facas, serra elétrica ou outros objetos que tenham contato direto com a carne a fim de evitar sérios prejuízos econômicos ao empresário, o que reflete diretamente no setor de economia mundial alterando significativamente o PIB brasileiro.

\section{REFERÊNCIAS}

ADAM, K. H.; BRUNT, J.; BRIGHTWELL, G.; FLINT, S. H.; PECK, M. W. Spore germination of the psychrotolerant, red meat spoiler, Clostridium frigidicarnis. Letters in Applied Microbiology, v. 53, n. 1, p. 92-97, 2011. Disponível em: < http://dx.doi.org/10.1111/j.1472-765X.2011.03071.x>. doi: 10.1111/j.1472765X.2011.03071.x

ADAM, K. H.; FLINT, S. H.; BRIGHTWELL, G. Reduction of spoilage of chilled vacuum-packed lamb by psychrotolerant clostridia. Meat Science, v. 93, n. 2, p. 310315, 2013. Disponível em: < http://dx.doi.org/10.1016/j.meatsci.2012.09.011>. doi: 10.1016/j.meatsci.2012.09.011

BOLTON, D. J.; CARROLL, J.; WALSH, D. A four-year survey of blown pack spoilage Clostridium estertheticum and Clostridium gasigenes on beef primal cuts. Letters in Applied Microbiology, n. 1, v. 61, p. 153-157, 2015. Disponível em: < http://dx.doi.org/10.1111/lam.12431 > doi: 10.1111/lam.12431

BONKE, R.; DREES, N.; GAREIS, M. Detection of psychrophilic and psychrotolerant Clostridium spp. in chilled fresh vacuum-packed meat using different PCR methods. FEMS Microbiology Letters, v. 363, n. 1, p. fnv218, 2016. Disponível em: < http://dx.doi.org/10.1093/femsle/fnv218>. doi: 10.1093/femsle/fnv218

BRODA, D. M.; BELL, R. G.; BOEREMA, J. A.; MUSGRAVE, D. R. The abattoir source of culturable psychrophilic Clostridium spp. causing "blown pack" spoilage of vacuum-packed chilled venison. International Journal of Applied Microbiology, v. 93, n.1, p. 817-824, 2002. Disponível em: < http://dx.doi.org/10.1046/j.13652672.2002.01757.x>. doi: 10.1046/j.1365-2672.2002.01757.x

COLLINS, M. D.; RODRIGUES, U. M.; DAINTY, R. H.; EDWARDS, R. A.; Roberts, T. A. Taxonomic studies on a psychrophilic Clostridium from vacuum-packed beef: Description of Clostridium estertheticum sp. nov. FEMS Microbiology Letters, v. 96, p. 1, p. 235-240, 1992. Disponível em: < http://dx.doi.org/10.1016/03781097(92)90410-P>. doi: 10.1016/0378-1097(92)90410-P

HELPS, C. R.; HARBOUR, D. A.; CORRY, J. E. L. PCR-based 16 S ribosomal DNA detection technique for Clostridium estertheticum causing spoilage in vacuumpacked chill-stored beef. International Journal of Food Microbiology, v. 52, n. 1, p. 
57-65, 1999. Disponível em: < http://dx.doi.org/10.1016/S0168-1605(99)00116-6>. doi: 10.1016/S0168-1605(99)00116-6

HERNÁNDEZ-MACEDO, M. L.; BARANCELLI, G. V.; CONTRERAS-CASTILLO, C. J. Microbial deterioration of vacuum-packaged chilled beef cuts and techniques for microbiota detection and characterization: a review. Brazilian Journal of Microbiology, v. 42, n. 1, p. 1-11, 2011. Disponível em: <http://dx.doi.org/10.1590/S1517-83822011000100001>. doi: 10.1590/S151783822011000100001

HEYNDRICKX, M. The importance of endospore-forming bacteria originating from soil for contamination of industrial food processing. Applied and Environmental Soil Science, $\quad$ v. 2011, p 1-11, 2011. Disponível em: <http://dx.doi.org/10.1155/2011/561975>. doi:10.1155/2011/561975

MACHADO, L. V. N.; AMIN, M. M.; CARVALHO, F. M. A.; SANTANA, A. C. Análise do desempenho das exportações brasileiras de carne bovina: uma aplicação do método constant-market-share, 1995-2003. Revista de Economia e AgronegócioREA, v. 4, n. 2, p. 195-218, 2015 . Disponível em: < http://www.rea.ufv.br/index.php/rea/article/view/ 80>

MILLS, J.; DONNISON, A.; BRIGHTWELL, G. Factors affecting microbial spoilage and shelf-life of chilled vacuum-packed lamb transported to distant markets: A review. Meat Science, v. 98, n. 1, p. 71-80, 2014. Disponível em: < http://dx.doi.org/10.1016/j.meatsci.2014.05.002>. doi: 10.1016/j.meatsci.2014.05.002

MOURA, E. S. R.; ABRANTES, M. R.; MENDES, C. G.; OLIVEIRA, A. R. M; SOUZA, E. S.; SILVA, J. B. A. Perfil higiênico-sanitário e perigos microbiológicos em abatedouros públicos. Revista Brasileira de Medicina Veterinária, v. 37, n. 3, p. 203-208, 2015. Disponível em: <http://www.rbmv.com.br/pdf_artigos/08-09-2015_2149RBMV\%200138.pdf.>

MOSCHONAS, G.; BOLTON, D. J.; SHERIDAN, J. J.; McDOWELL, D. A.. The effect of heat shrink treatment and storage temperature on the time of onset of "blown pack" spoilage. Meat science, v. 87, n. 2, p. 115-118, 2011. Disponível em: <doi: http://dx.doi.org/10.1016/j.meatsci.2010.09.007>. doi:10.1016/j.meatsci.2010.09.007

POTHAKOS, V.; DEVLIEGHERE, F.; VILLANI, F.; BJÖRKROTH, J.; ERCOLINI, D. Lactic acid bacteria and their controversial role in fresh meat spoilage. Meat Science, v. 30, n. 109, p. 66 - 74, 2015. Disponível em: < http://dx.doi.org/10.1016/j.meatsci.2015.04.014> doi:10.1016/j.meatsci.2015.04.014

SILVA, A. R.; TAHARA, A. C. C.; CHAVES, R. D.; SANT'ANA, A. S.; FARIA, J. A. F.; MASSAGUER, P. R. Influence of different shrinking temperatures and vacuum conditions on the ability of psychrotrophic Clostridium to cause 'blown pack' spoilage in chilled vacuum-packaged beef. Meat Science, v. 92, n. 4, p. 498-505, 2012. Disponível em:<http://dx.doi.org/10.1016/j.meatsci.2012.05.017>. doi:10.1016/j.meatsci.2012.05.017 
YANG, X.; WANG, H.; BADONI, M. Effects of meat $\mathrm{pH}$ and the initial numbers of spores of Clostridium estertheticum on the development of blown pack spoilage of vacuum-packaged beef. International Journal of Food Science \& Technology, v. 49, n. 7, p. 1619-1625, 2014. Disponível em: <http://dx.doi.org/10.1111/ijfs.12457>. doi: 10.1111/ijfs.12457. doi: 10.1111/ijfs. 12457 